\title{
Evaluating the Academic Trend of RFID Technology based on SCI and SSCI Publications from 2001 to 2014
}

\author{
Masoud Shakiba $^{1}$, Azam Zavvari ${ }^{2}$, Nader Ale Ebrahim ${ }^{3}$, Mandeep Jit Singh ${ }^{2}$ \\ ${ }^{1}$ School of Information Technology, Monash University, 47500 Bandar Sunway, Selangor, Malaysia \\ (Correspondent author email: masoud.shakiba@monash.edu) \\ ${ }^{2}$ Department of Electrical, Electronic and Systems Engineering, Faculty of Engineering and Built \\ Environment, Universiti Kebangsaan Malaysia \\ ${ }^{3}$ Research Support Unit, Centre for Research Services, Institute of Research Management and Monitoring \\ (IPPP), University of Malaya, Malaysia
}

\begin{abstract}
Radio Frequency Identification (RFID) is one of the most influential technologies of the twenty-first century. Today, RFID technology is being applied in a wide array of disciplines in science research and industrial projects. The significant impact of RFID is clearly visible by the rate of academic publications in the last few years. This article surveys the literature to evaluate the trend of RFID technology development based on academic publications from 2001 to 2014. Both bibliometric and content analyses are applied to examine this topic in SCI-Index and SSCI-Index documents. Based on the bibliometric technique, all 5,159 existing RFID documents are investigated and several important factors are reviewed, including contributions by country, organizations, funding agencies, journal title, authors, research area and Web of Science Category. Moreover, content analysis is applied to the top 100 most cited documents and based on their contents, these top 100 documents are classified into four different categories with each category divided in several sub-categories. This research aims to identify the best source of the most cited RFID papers and to provide a comprehensive road map for the future research and development in the field of RFID technology in both academic and industrial settings. Six key findings from this review are (1) the experimental method is the most popular research methodology, (2) RFID research has been a hot area of investigation but will branch out into related subset areas, (3) South East Asia is positioned to dominate this research space, (4) the focus of research up to now has been on technical issues rather than business and management issues, (5) research on RFID application domains will spread beyond supply chain and health care to a number of different areas, and (6) more research will be related to policy issues such as security and privacy.
\end{abstract}

Keywords: RFID; radio frequency identification; historical literature review; bibliometric analysis; classification framework. 
Post-Print version of: Shakiba, M., Zavvari, A., Ale Ebrahim, N., \& Singh, M. J. (2016). Evaluating the academic trend of RFID technology based on SCI and SSCI publications from 2001 to 2014. Scientometrics 1-24.

http://dx.doi.org/10.1007/s11192-016-2095-y

\section{$1 \quad$ Introduction}

Radio frequency identification (RFID) is a technology that identifies tagged objects via radiated RF signals. Today, RFID is widely used in tracking objects, such as for automated identification and data capture, supply chain management, tracking, access control, and asset management (Shakiba, Singh, Sundararajan, Zavvari, \& Islam, 2014). Compared to barcode technology, RFID has the ability to read and write data, most RFID tags have a greater memory capacity, provides for a faster identification procedure, has greater read distance, and supports concurrent identification of multiple tags. In addition, it does not need human mediation or line-of-sight (Shakiba, Sundararajan, Zavvari, \& Islam, 2013; Symonds, Ayoade, \& Parry, 2009).

Curtin, Kauffman, and Riggins (2007) proposed a comprehensive research agenda for the study of the adoption, usage and impact of RFID nearly a decade ago. In that paper, the authors outlined a number of important organizational and management related research questions pertaining to RFID. They predicted that the technical issues related to RFID would be examined in great detail by the engineering and computing academy, but if the non-technical business issues were not investigated then adoption of the technology would lag. Considerable literature pertaining to RFID was published between the decade-plus period from 2001 to 2014 and the aim of this study is to broadly evaluate and categorize the RFID literature during this time in order to support the base and knowledge development within this domain. In particular, in order to investigate the overall trend of RFID research, the targets of this study include:

1. Provide a classification framework that is based on theory and informed by existing RFID publications on the SCI-Index and SSCI-Index databases.

2. Apply this organizational structure to summarize the significant aspects of the voluminous RFID literature.

3. Perform quantitative and qualitative evaluation and exploration of the RFID literature with respect to both the accomplished milestones and noteworthy matters respectively, which would benefit both research scholars and professionals.

4. Identify key researchers and gaps in the RFID literature in order to stimulate future studies.

The structure of the paper is as follows: Section 2 considers the research methodology and materials used in this paper. Section 3 presents the bibliometric analysis of RFID publications, followed by a content analysis of the top 100 RFID papers based on citation count in Section 4. In Section 5 we note limitations of our study, followed by Section 6 where we summarize our findings, offer concluding remarks, and suggest directions for future research.

\section{$2 \quad$ Research Methodology and Material}

The main objectives of this study are to assess the academic trends of RFID technology development based on high quality published manuscripts and provide a roadmap for future research. In this regards, the Science Citation Index Expanded (SCI) and Social Science Citation Index (SSCI) databases were selected as the sources for the high quality manuscript documents. SCI and SSCI were obtained by a subscription from ISI, Web of Science (WoS), with access provided by the library of Universiti Kebangsaan Malaysia (The National University 
Post-Print version of: Shakiba, M., Zavvari, A., Ale Ebrahim, N., \& Singh, M. J. (2016). Evaluating the academic trend of RFID technology based on SCI and SSCI publications from 2001 to 2014. Scientometrics 1-24.

http://dx.doi.org/10.1007/s11192-016-2095-y

of Malaysia). The other indexing categories of the WoS such as Art \& Humanities Citation Index (A\&HCI) and conference proceedings were excluded from the investigation process. As mentioned, all analysis and perceptions are only based on academic publications (SCI and SSCI databases) and other information and publications such as published documents in other databases, industrial reports, commercial news, general information resources, and white papers and so on were not involved in this study.

To achieve the above objectives, two different strategies were applied in this research: bibliometric analysis and content analysis. In this order, the SCI and SSCI databases were systematically searched for RFIDrelated materials published from 01 January, 2001 to 31 December, 2014, with an update from the databases on 31 March, 2015. All documents which included "RFID" or "radio frequency identification" in the title, abstract or keywords were captured as presented at the attached file (AttachmentI_RFID_RawData.xlsx). The bibliometric analyses quantitatively investigate all document characteristics such as country of origin, organization affiliation, funding agency, journal, year published, research area, WoS category, author, and number of times cited. The first strategy of gathering documents related to "RFID" or "radio frequency identification" provides comprehensive historical information related to RFID technology. Based on the number of published documents, we quantitatively ranked the different characteristics of the documents, but to provide a clear view of RFID academic trends we also considered qualitative parameters of the documents including citation, Avg citation, self-citation and h-index as defined below:

- Citation: A citation is a reference to a published document. We used only the SCI and SSCI databases such that to count as a citation, both cited and citing documents must be documented in these databases, and other citations are not considered.

- Avg. citation: The average number of citations, which is the total citations of all documents in a category, divided by the number of documents in that same category.

- Self-citation: a citation where the cited and citing documents share at least a same author, a same journal, or a same category (Couto, Grego, Pesquita, \& Verissimo, 2009).

- h-index: The h-index "gives an estimate of the importance, significance, and broad impact of a scientist's cumulative research contributions". The h-index is defined as the number of papers, h, with citations greater than or equal to h. For example, an h-index of 25 indicates that the author has at least 25 papers with at least 25 citations each (Hirsch, 2005).

To give the right picture of academic trends in this area, in addition to the two main terms (RFID and radio frequency identification) several other RFID-related keywords were also investigated and analyzed including Internet of Things (IoT), wireless sensor networks, ubiquitous computing, automatic identification, wireless communication, Near Field Communication (NFC), Global Positioning System (GPS), Electronic Product Code (EPC), and Ultra High Frequency (UHF).

The second strategy we used was to analyze the contexts of the 100 most-cited documents. To find the top 100 documents, we ranked all 5,159 captured documents from most to least cited (An excel file is attached as a supplementary data to show the all 5,159 documents' information, under the file name: AttachmentI_RFID_RawData.xlsx). Citation analysis was based primarily on the impact factor as defined by the Journal Citation Reports (JCR) and on Citation per Publication (CPP), which are used to assess the impact of 
Post-Print version of: Shakiba, M., Zavvari, A., Ale Ebrahim, N., \& Singh, M. J. (2016). Evaluating the academic trend of RFID technology based on SCI and SSCI publications from 2001 to 2014. Scientometrics 1-24.

http://dx.doi.org/10.1007/s11192-016-2095-y

journals. In this paper, we sort the documents based on average citations per year, which is defined as the ratio of the number of citations the publication has received to the length of time since publication (Chao, Yang, \& Jen, 2007). The full text of the top 100 most-cited articles were carefully reviewed, not only using bibliometric analysis, but each article was classified using a single category for any diversity characteristic. To help frame a series of research agenda items related to RFID, we will briefly consider the top 100 cited papers in four different categories: RFID Technology, RFID Applications, Policy Issues, and Others. For each category, we further assign articles to a sub-category. These four categories and sub-categories are defined based on the contexts of the investigated documents. To minimize the errors, two of the four researchers in the team independently classified each of the articles. If there was a difference in the selection of the two researchers, then the article in question was discussed until an agreement was reached as to whether it should be included in the final set (E. Ngai, Moon, Riggins, \& Yi, 2008).

Bibliometric Analysis of RFID Publications

As mentioned before, the keywords "RFID" and "radio frequency identification" were used to search in the SCI and SSCI databases in the range of years 2001 to 2014. A total of 5,159 documents were found which in total have 45,568 citations. In this section, we present the bibliometric analyses we applied to provide future researchers and investigators a general road map of RFID academic trends. In this case, we analyzed all 5,159 discovered documents and the top 100 most-cited documents using a trend analysis for the distribution status (AttachmentII_RFID_AnalysisData.xlsx).

\subsection{Distribution by country}

Based on analyzing the attached excel file (AttachmentI_RFID_RawData.xlsx), and as shown in the "Attachment II, Table I_Countries", all RFID documents were published by 75 different countries, where the top 10 countries based on the number of publications are listed in the attached table (see Fig 1 for a shaded-coded map). The number of publications in different countries is extracted based on the authors' affiliations. For documents with authors from different countries we multiple count the document. For example if there is a document with two authors, from two different countries (we assume US and UK) as their affiliations; then we count the document twice and add both US and UK publication number by one. As presented in the attached table, the United States (USA) was the most prolific country publishing RFID-related documents with more than 23.5 percent of all the publications or 1,215 total published documents, as well as 48 percent of the most-cited documents. Further, with 18,440 total citations, the USA accounts for more than 41 percent of all citations of RFID documents in this data set. The USA h-index is 60 which double's China's h-index of 30 . Based on the number of publications the USA, China and South Korea are the first three countries, but based on the average citations per document, USA, Italy and Germany with $15.18,13.56$, and 11.71 respectively are the counties producing the most cited papers. It is interesting that the top ten countries produce nearly 85 percent of the documents and 95.8 percent of the total citations. Based on attached data sheet (Attachment I and Attachment II), USA with 1,215 publications, 18,440 total citations, 15.18 average citation per document, 60 as an h-index, and 48 documents in the top 100 cited documents is the country with the most contribution toward RFID publications both in terms of quantitative impact (number of publications) and qualitative impact (high quality publications). The next notable finding is the rate of self-citation. From this perspective, China, Taiwan and 
Post-Print version of: Shakiba, M., Zavvari, A., Ale Ebrahim, N., \& Singh, M. J. (2016). Evaluating the academic trend of RFID technology based on SCI and SSCI publications from 2001 to 2014. Scientometrics 1-24.

http://dx.doi.org/10.1007/s11192-016-2095-y

South Korea with respectively 15.73, 15.21 and 11.75 percent demonstrate the higher rate of the self-citation; and the Germany with only 2.25 percent self-citation shows the lower rate.

Fig 1. RFID Map: contribution of different countries with RFID technology, based on number of publications.

\subsection{Distribution by organization}

All documents in this study are published by 2,927 different universities, institutes or organizations. "Attachment II, Table II_Organizations" shows the top 20 organizations based on the number of RFID publications in the SCI and SSCI databases. In terms of total publications, Hong Kong Polytechnic University of China, Electronics and Telecommunications Research Institute from Korea and Tampere University of Technology from Finland with 77, 65, and 64 RFID publications respectively are the top three RFID research institutes. Based on the quality of publications (average citation per document), Hong Kong University of Science and Technology from China, University of Washington and Georgia Institute of Technology from USA, with 49, 37, and 61 published documents, but 20.63, 19.62, and 18.92 average citations per document, are the top three pivotal institutes in the field of RFID research. Based on the self-citation ratio, the University of Florida from USA, University of Hong Kong from China, and the Tampere University of Technology from Finland with the 14.79, 12.84 and 10.24 selfcitation percentage are the organization with the most self-citation, in the other hand, the National Taiwan University with only 0.81 percent of self-citation is the best organization from this point of view. As presented at the "Attachment II, Table II_Organizations", among the top 20 organizations in the field of RFID, 16 organizations are from the South East Asia, and only 3 institute from USA, and just a single university from the Europe, which is need to be considered.

\subsection{Distribution by funding agency}

The next important subject matter that we can extract form the raw data (Attachment I) is the top organizations that financially supported RFID research projects based on the number of publications. Funding agencies are the government or non-government organizations that provide research and academic funding in the form of research grant or scholarships. These data were extracted based on the acknowledgement parts of the documents and only agencies acknowledged are noted. As illustrated in the "Attachment II, Table III_FundingAgencies" National Natural Science Foundation of China with 311 publications is ranked as a top funding agency which is followed by National Science Council, Taiwan with 168 publications and European Commission with 164 publications in the second and third rank.

\subsection{Distribution by source title}

All published RFID documents existing in the SCI and SSCI databases are published in 1,104 different journals. As illustrated at the "Attachment II, Table IV_SourceTitles", the Microwave and Optical Technology Letters with 175 published documents is the highest ranked journal in RFID based on number of publications. In this table, IF represent the journal impact factor which is the total number of citations of the journal divided by all published documents during last two years (REUTERS, 2010): 
Post-Print version of: Shakiba, M., Zavvari, A., Ale Ebrahim, N., \& Singh, M. J. (2016). Evaluating the academic trend of RFID technology based on SCI and SSCI publications from 2001 to 2014. Scientometrics 1-24.

http://dx.doi.org/10.1007/s11192-016-2095-y

$$
\text { Impact factor }=\frac{\text { total citations in last two years }}{\text { total published documents in last two years }}
$$

Publications such as lecture notes or conference proceedings do not have impact factors and are therefore listed as being indexed in the mentioned databases. Based on impact factor, journals are categorized in four different quartiles, with Q1 being the top 25\% and so on. Based on the impact factor, the top journal in contribution with RFID is Nature with 42.351 impact factor. It is interesting that the highest impact journal published the highest cited paper entitled "Ultralow-power organic complementary circuits" by Hagen Klauk, Ute Zschieschang, Jens Pflaum, and Marcus Halik from Germany in 2007. That paper has received 700 citations making it the most cited paper in the RFID literature. However, that is the only RFID-related paper Nature published during that time due to Nature's wide topical scope.

\subsection{Distribution by publication year}

Fig 2 shows the distribution by year for all published documents and the top 100 most-cited papers. Based on Fig 2, there has been a sharp increase in RFID research, insofar as it shows just under 54 times growth in number of publication from 2001 with 13 documents to 2014 with 699 published documents. On the other hand, the top 100 cited documents follows a different trend, where the major numbers of top cited documents were published in 2006, 2007, and 2008 respectively. Since the top 100 cited papers were selected based on the average number of citations per year during the investigated time period we need to consider two important facts:

i. The cited half-life of the investigated journals is approximately 6 to 7 years. In other words, the highest citation of papers is expected to be achieved 6 to 7 years after the time of publication. Based on this, older papers during the investigated time period would present a lower average.

ii. The citation procedure is a time consuming process, approximately between 1 to 2 years. Based on this point newly published documents achieve less citation.

Based on these two points we expect the highest average citation for documents published 6 to 7 years prior to the gathering of data. Since this study investigate the documents through 2014, this explains why there are more highly cited papers in 2006 to 2008 as presented at Fig 2.

Fig 2. Distribution by publication year from 2001 to 2014

Fig 3 illustrates the top 10 countries for publications through the studied period. It is observable that there is a strong interest in RFID in South East Asian countries during the last few years. We can see that China surpassed the USA in 2013 and 2014 based on the number of published documents. Furthermore, South Korea and Taiwan are located at the next positions after the USA.

Fig 3. Distribution by publication year from 2001 to 2014 for top 10 countries

\subsection{Distribution by author}

Top 10 authors who publish papers related to RFID with their publication number, citations, average citations per document, self-citation and h-index is extracted from the raw data and is available at the "Attachment II, 
Post-Print version of: Shakiba, M., Zavvari, A., Ale Ebrahim, N., \& Singh, M. J. (2016). Evaluating the academic trend of RFID technology based on SCI and SSCI publications from 2001 to 2014. Scientometrics 1-24.

http://dx.doi.org/10.1007/s11192-016-2095-y

Table V_Authors". As shown, Leena Ukkonen, professor at Tampere University Technology from Finland is the top author in the field of RFID based on the number of publications with 49 RFID papers. Of the 5,159 published documents in the SCI and SSCI databases, there are 142 documents by anonymous authors. In total, there are 17,907 authors who have published within these database listings. The maximum number of authors for one paper is 24 authors and on average there are 3.44 authors for a single paper. Attached "Attachment II, Table V_Authors" ranks the authors based on the number of publications (quantitatively investigate the authors). But based on the quality of documents, form the attached table, only Manos M. Tentzeris with 3 high cited paper and Gaetano Marrocco with 1 high cited paper have papers in top 100 cited documents - and other authors in attached "Table V_Authors" do not have any papers in the top 100 cited documents. On the other hand, there are authors who focus more on quality than quantity. For example, K. V. Seshagiri Rao from Intermec Technology Corp, USA has published only 10 documents but with an average citation 78.2 and with 3 papers in the top 100 cited documents or Ari Juels from Cornell University, USA has published 12 RFID documents and an average citation 73.58, with 3 papers in the top 100 cited documents. It is also notable, where the Juels and Rao have only $1 \%$ and $1.7 \%$ self-citation respectively, the authors listed at attached "Table V_Authors", such as Piramuthu, Smail, and Zheng have a high rate of self-citation on average per document with $21.32 \%, 18.64 \%$ and $18.08 \%$ respectively.

\subsection{Distribution by research area}

There are some research areas defined by Thomson Reuters based on the topics and the scopes of the journals. Journals publish documents in different research areas, where some journals publish in more than one research area. Top 20 research areas in contribution to the RFID literature where there are 103 different research areas with contributions to RFID are extracted from the raw data and illustrated at the "Attachment II, Table VI_ResearchAreas". As presented in attached table, Engineering (2,881), Computer Science (1,538), Telecommunication (1,279), Physics (327), and Operations Research \& Management Science (306) are the five top research areas with contributions toward the RFID literature. The five areas at the top of the 100 most cited papers are the same and in the same order, but the Materials Science also included - Engineering (51), Computer Science (26), Material Science (15), Telecommunication (14), Physics (14) and Operation Research \& Management Science (13). Based on the attached "Table VI_ResearchAreas", the Science Technology Other Topics, Operation Research Management Science and Construction Building Technology by 14.85, 14.31, and 13.78 average citation per document are the most cited documents.

\subsection{Distribution by Web of Science category}

Based on subjects, journals are categorized in different Web of Science subject categories by Thomson Reuters. Based on these categories, all RFID documents are published in 178 different subjects, where some journals belong to more than one subject category. Based on WoS Subject category, as presented in "Attachment II, Table VII_WoS", Engineering Electrical Electronic (2,178), Telecommunications (1,279), Computer Science Information System (744), Computer Science Theory Methods (319), and Computer Science Artificial Intelligence (318) represent the top five subjects in RFID research. In the top 100 most-cited papers, Engineering Electrical \& Electronic with 33 documents is the top category, where Telecommunications and Material Science with 14 and Operations Research \& Management Science with 13 documents are in the second and third rank. 
Post-Print version of: Shakiba, M., Zavvari, A., Ale Ebrahim, N., \& Singh, M. J. (2016). Evaluating the academic trend of RFID technology based on SCI and SSCI publications from 2001 to 2014. Scientometrics 1-24.

http://dx.doi.org/10.1007/s11192-016-2095-y

Based on the average citation per document the Operation research \& Management Science with 14.31 cite per document, published highest cited documents.

\subsection{Number of times cited}

As we already mentioned there are 5,159 published documents in the SCI and SSCI databases with contributions to RFID. These documents are cited 45,568 times. On average a paper is cited 8.83 times, where the h-index of RFID documents is 80 ; that is, there are 80 documents that have 80 or more citations. It is interesting to note that more than 8.8 percent of all the citations belong to the top 10 most cited papers. The top 100 papers account for about 30 percent of all citations and around 63 percent of all citations belong to the first 10 percent most cited papers. Not all RFID published documents have citations. Our count shows that 1,654 of the documents or 32\% have no citations. Fig 4 illustrates the distribution of RFID documents by citation per year, from 2001 to 2014. As shown in Fig 4, the trend of citation is increasing sharply during the mentioned period, which indicates an increase in interest in this area from academics.

Fig 4. Distribution by citation per year from 2001 to 2014

In section 3, several characteristics of the RFID published documents were analyzed, and all the discussed characteristics information as a raw data (Attachment I) and as analysis data (Attachment II) are available. Attachment II involve some additional information, which analyzed some other characteristics of the documents.

\section{Content Analysis and Classification of the Top 100 Most-Cited RFID Papers}

Our framework includes a content-oriented classification of the RFID literature. First, we classified the top 100 most cited papers within nine different research methodologies as follows: Experimental, Review, Simulation, Case Study, Theoretical Analysis, Propose a Model, Introduction, Framework Extension and Software Development. Next, we classified each of the 100 papers based on the content and the subject of the study into four different categories: RFID Technology, RFID Applications, Policy Issues, and Others. Then each category is divided into several subcategories. The details of our classification scheme based on research methodology and subject categories are given in the following section.

\subsection{Classification based on research methodology}

We categorize the top 100 most-cited papers into nine different categories based on the research methodologies applied in the articles. Here, we describe all nine methodologies used to prepare the articles. The methods are sorted based on the frequency used across the 100 papers.

i) Experimental:

Experiments are an essential part of the scientific method in the physical sciences such as engineering. In experimental method, the proposed idea or theory are physically implemented and tested under particular considerations and environmental effects. 
Post-Print version of: Shakiba, M., Zavvari, A., Ale Ebrahim, N., \& Singh, M. J. (2016). Evaluating the academic trend of RFID technology based on SCI and SSCI publications from 2001 to 2014. Scientometrics 1-24.

http://dx.doi.org/10.1007/s11192-016-2095-y

ii) Review:

Summarize, analyze, and criticize previously published articles.

iii) Simulation:

iv) Case Study:

v) Theoretical Analysis:

vi) Propose a Model:

vii) Introduction:

viii) Framework Extension:

ix) Software Development: Based on an existing idea a new interface, middleware, or software artifact is developed.

As illustrated in Fig 5, papers based on Experimental results tend to be cited most often with 42 publications, followed by Review papers with 32 papers and Simulation papers with only 9 papers. An interesting finding shown in the Table 1 is that while there are 42 Experimental papers, the research methodology with the highest average number of citations per document are the two papers that propose a model with 188 citations per document. Followed by this are Review papers, Experimental papers, and Theoretical Analysis with about 141, 131 and 109 average citations per document respectively.

Fig 5. Frequency of nine research methodologies across the top most cited 100 papers in RFID

Table 1. Times cited for nine different research methodologies

\subsection{Classification based on the subject of study}

The 100 most-cited papers were investigated in detail based on the subject of the studies. In this regard, we classified the articles within the four different major subject groups. Table 2 presents these four major groups and the number of publications in each group. Based on the results, RFID Technology with 36 publications is the most frequent subject with 5,590 total citations. However, the Policy Issues group with only eight articles has the 
Post-Print version of: Shakiba, M., Zavvari, A., Ale Ebrahim, N., \& Singh, M. J. (2016). Evaluating the academic trend of RFID technology based on SCI and SSCI publications from 2001 to 2014. Scientometrics 1-24.

http://dx.doi.org/10.1007/s11192-016-2095-y

highest average citations with 184.63 citations per paper. The four major subject categories and their subcategories are presented in the Fig 6.

Table 7 gives a summary of all 100 top cited articles in the classification scheme. For each paper, we list the total number of citations followed by the average citations per year. This should be a helpful resource for those researching RFID papers.

Table 2. Times cited for four different subject categories

Fig 6. Classification of top 100 RFID papers based on the subject of study

\subsubsection{RFID Technology}

Readers, tags, antennas, software, middleware, and computing software are included in RFID based systems. Based on the reviewed papers, RFID Technology has been divided into the following three sub-categories:

\section{i. Tag design and fabrication}

RFID systems are integrated with tags. RFID tags are divided into active, passive and semi-passive tags. Active tags having an on-board power battery and can transmit their IDs without require to the external power supplier. On the other hand, passive tags have not an on-board energy source, therefore they response back the readers' signals, where the signals supply the energy of the ID transmission process and any further communications. Moreover, semi-passive tags that can act as active or passive tags, where they have their own on-board power supplier, but in the interrogation zone of the reader, they can use the readers' signals to support the energy. Diverse RFID tags are available in the market, however, memory based integrated circuits are typically incorporated in the RFID circuits. All testing sessions, design plans, production processes, power vendors or material for RFID tags are included in this sub-classification.

\section{ii. Communication infrastructure}

The wired and wireless networks collectively form the communication infrastructure over which a series of information transfer actions take place that deliver the data stored on a tag to the reader. Research articles that include protocols and communication criteria, network connectivity matters and anti-collision algorithms are all incorporated into this particular category.

\section{iii. Antenna design}

The antenna is a key element in any RFID system. The readers and tags require the antenna to facilitate communication. Between the tag and the reader, data sharing is carried out by the antennae communication channel. Moreover, an antenna configuration holds a significant role in evaluating the coverage area and precision of a tag link. On the other hand, in passive tags' communication structure, the antenna draws power from the reader's signal to both power the tag and send data. As a result, articles focusing on RFID antennae are included in this category. 
Post-Print version of: Shakiba, M., Zavvari, A., Ale Ebrahim, N., \& Singh, M. J. (2016). Evaluating the academic trend of RFID technology based on SCI and SSCI publications from 2001 to 2014. Scientometrics 1-24.

http://dx.doi.org/10.1007/s11192-016-2095-y

Table 3 shows the number of papers belonging to the RFID Technology group. Of the 36 paper in this group, about 58 percent (21 papers) are related to tag design and fabrication, where the other two sub-categories are represented by about 22 percent and 19 percent of the publications by the technology category.

Table 3. Publications in the RFID Technology sub-categories

\subsubsection{RFID Applications}

Production, supply chain management, and logistics systems frequently employ RFID. However, the vision and range of applications that are using RFID is much broader than these systems. RFID is being pilot tested and deployed in many more dynamic and robust types of applications. RFID technology is a fundamental key element for implementing electronic commerce, maintaining efficient supply chain management, employing logistics tracking systems, and having effective resource management. To have successful enterprises today, it is essential to monitor all resources, products, employees, and have efficient electronic relationships with suppliers and customers. Heinrich indicates that RFID is becoming the hi-tech and thrilling next generation business tool with respect to a diversity of applications (Heinrich, 2005). The RFID Applications category is therefore further divided into a number of sub-categories based on the articles investigated here to include:

- $\quad$ Food Industry \& Agriculture

- $\quad$ Supply Chain Management

- $\quad$ Retailing \& E-commerce

- $\quad$ Health Care

- $\quad$ Tracking System \& Localization

- $\quad$ Resource Management

- $\quad$ Social Science \& Education

- Gas Detection

- Intelligent Products

Table 4 illustrates these sub-categories of RFID applications and their number of publications. Based on the table, of the 33 papers in the RFID Applications group, Food Industry \& Agriculture, Supply Chain Management (SCM), and Retail Business \& E-commerce are the most frequent applications with more than 21, 18, and 15 percent of publications within this group respectively, followed by Health Care with 12 percent and Tracking System \& Localization, Resource Management, and Social Science \& Education with about 9 percent of the published documents in this category.

Table 4. RFID Applications sub-categories publication number

\subsubsection{Policy Issues}

These issue can be divided into sub-categories of security and privacy as shown in Table 5. Of the eight articles six ( 75 percent) pertain to the security sector and 2 documents ( 25 percent) pertain to the privacy area. 
Post-Print version of: Shakiba, M., Zavvari, A., Ale Ebrahim, N., \& Singh, M. J. (2016). Evaluating the academic trend of RFID technology based on SCI and SSCI publications from 2001 to 2014. Scientometrics 1-24.

http://dx.doi.org/10.1007/s11192-016-2095-y

\section{i. $\quad$ Security}

Security of confidential data and protection from illegal access and operation are the key matters pertaining to security (Bhuptani \& Moradpour, 2005). Being a wireless technology, RFID systems are subject to many security threats with illegal tracking of the RFID tags being the most significant one. Other major security hazards such as integrity, privacy, confirmation, authority, non-censure, and ambiguity can only be defeated by implementing robust and enhanced security into the system (Knospe \& Pohl, 2004).

\section{ii. Privacy}

RFID related privacy issues include likely misuse of data by allowed users resulting in incursion and infringement of individual or company secrecy (Bhuptani \& Moradpour, 2005). Consumer advocates are calling for greater regulation and codes of practice, especially for tags that are readable worldwide because of the risk that they pose to personal location privacy. Since everyone is concerned about privacy, RFID advocators have acknowledged that procedures such as "kill" functionality and confining the chip range can be incorporated into a system to avoid private data from being used illegally. Hence, a number of issues are captured in this subcategory, including RFID/human interaction, legal security, RFID protection issues, and records safety laws.

Table 5. Policy issues sub-categories publication number

\subsubsection{Others}

There are many other issues covering important aspects of RFID technology like fabrication of electronic devices, Internet of Things, general introduction of RFID systems, bibliometric studies, review papers, and research on sensor networks. As shown in the Table 6, there are 23 documents in this category, with fabrication of electronic devices being the most frequent representing more than 43 percent of the papers ( 10 documents), to sensor networks with only one document located at the end of this group.

Table 6. Others subjects sub-categories publication number

As previously mentioned, Table 7 presents the summary of the top 100 papers by categories and subcategories, where we list the authors, publication year, total citations, and average citations per year respectively for each paper (see the Reference section for full reference citation). We believe this table will be a useful source for those researching RFID papers.

Table 7. Classification of the reviewed literature

\section{$5 \quad$ Limitations}

The applied methodology in this research has the following limitations:

- The study is only based on academic publications, where we do not investigate industry and market information regarding RFID technology. 
Post-Print version of: Shakiba, M., Zavvari, A., Ale Ebrahim, N., \& Singh, M. J. (2016). Evaluating the academic trend of RFID technology based on SCI and SSCI publications from 2001 to 2014. Scientometrics 1-24.

http://dx.doi.org/10.1007/s11192-016-2095-y

- $\quad$ To collect the academic publications, only the SCI and SSCI indexed documents were selected. Hence we lose the opportunity to consider high quality papers in other databases and indexes. However, while this means that the review is not exhaustive, we believe that it is comprehensive.

- $\quad$ The quality of the papers evaluated is based on the number of citations of the paper. The citation count is also limited to the SCI and SSCI indexed documents and citations from other documents are not included. Further, in our study citation presents the quality of the paper; other criteria of the publication such as scope of study, methodology, transfer to industry and so on are not investigated when evaluating the top papers.

\section{Discussion and Conclusion}

In this review paper, we applied the bibliometric method to investigate all RFID documents in the SCI Index and SSCI Index from 2001 to the end of 2014. All 5,159 existing documents are categorized based on several different elements to show the trends in RFID research during this period of time. The most influential countries, journals, organizations and researchers are presented. Furthermore, the 100 most-cited RFID documents are investigated in detail based on their content and classified into nine different groups based on the applied research methodologies, followed by a categorization based on topic into four categories and sub-categories.

We believe the key findings of this research can be listed as follows:

i. Our review classifies the top 100 most-cited RFID articles into nine different research methodologies as shown in Table 1 and Fig 5. Our findings illustrate that by far the most popular approach is to apply the experimental method accounting for 42 percent of the top articles. Since papers that applied the experimental methodology are based on real observed data using a controlled experiment, their results are highly reliable and replicable to other settings which helps account for their citation noteworthiness and high quality. Hence it is apparent that experimental studies are very attractive for researchers and receive more citations. In addition, the technical nature of RFID lends itself to a research mindset of experimentation to solve technical problems as the technology matures. We expect the experimental methodology will continue to dominate this area for the next decade. However, as these technical problems are addressed we also expect to see other methodologies employed more frequently to address the non-technical such as incentives to encourage adoption, best practices for usage, and approaches to achieve value maximization. To this end we expect to see more case studies, theoretical analysis, and proposed models to address these issues.

ii. According to the rates of publication in the investigation period from 2001 thru 2014, RFID had only 13 published documents in 2001 but then exhibited a sharp increase in publication activity during the study period resulting in an increase of more than a factor of 53 to reach a total of 699 published documents in 2014. An even sharper increase occurred in the citation numbers for these papers. RFID documents were cited seven times in 2002, but demonstrated more than a thousand times increase citations in 2012 and after. Therefore, we believe we can state that RFID has become a hot research area during the past ten years. Based on the publication and citation trends, we anticipate that research on RFID topics will 
Post-Print version of: Shakiba, M., Zavvari, A., Ale Ebrahim, N., \& Singh, M. J. (2016). Evaluating the academic trend of RFID technology based on SCI and SSCI publications from 2001 to 2014. Scientometrics 1-24.

http://dx.doi.org/10.1007/s11192-016-2095-y

continue to increase and evolve over the next decade, but shift toward RFID-related subset areas. We expect to see a relative decline in RFID-specific research but an increase in topics related to RFID as the field matures and broadens to other areas. RFID related topics in which we expect to see increased publication activity include the Internet of Things (IoT), wireless sensor networks, ubiquitous computing, automatic identification and more application-based studies. The papers noted here, especially the most highly cited papers, should provide a strong foundation on which to build a growing body of literature in these related areas.

iii. In our review, we find that in total 75 different countries have contributed to the growing publication stream of RFID research papers. Industrialized countries have had more contributions in this regards, with the USA accounting for about a quarter of the activity due to 1,215 published documents, and 48 percent of the 100 most-cited articles. While the USA has more publications up to this time, based on “Attachment II, Table II_Organizations”, there are 16 institutes and universities in South East Asia among the top 20 world organizations advancing research in this area. At the same time, as shown in “Attachment II, Table III_FundingAgencies”, it is observable that South East Asia is taking RFID very seriously where six of the top 10 funding agencies are located. This focus is easily demonstrated by a quick check of recent patterns of RFID search terms by regional interest on Google Trends. Consequently, we expect the ratio of RFID-related publications originating from South East Asia countries will increase sharply over the next decade. The recent trends shown in Fig 3 help justify this expectation. From this study, we conclude that due to its commitment to advancing RFID knowledge South East Asia is positioned to overtake North America and Europe in this area and dominate this field in the coming years. Combining this point with the previous point, we believe South East Asia may be poised to dominate the emerging RFID-related subset fields as well.

iv. As shown in "Attachment II, Table IV_SourceTitle", this study highlights that the majority of research has been published in technical journals such as IEEE publications and other engineering outlets, and according to "Attachment II, Table VI_ResearchAreas" tends to focus on technical research areas such as engineering, computer science and telecommunication. This is understandable since our framework category with the most highly-cited publications was for RFID Technology with a focus on tag design, antennae design and development of the communication infrastructure. While the SSCI database and publication outlets related to management, business and economics are investigated in this study, the ratio of publications on technical issues is much higher than non-technical issues such as business and management issues in the existing literature stream. This is evidenced by the fact that the SCI database produced ten times more RFID-related papers than the SSCI database. The scant number of business and management related publications is surprising considering that one of the papers on the most-cited list specifically calls for, and suggests research directions for, research in this area (Curtin et al., 2007). For example, standards development naturally lends itself to technical papers, however the role of standards is also critical for adoption by numerous parties which then allows externality benefits to occur. It is clear that if organizations are to take full advantage of RFID and related technologies these "soft" issues related to adoption, incentives, and value allocation must be examined. Some progress has 
Post-Print version of: Shakiba, M., Zavvari, A., Ale Ebrahim, N., \& Singh, M. J. (2016). Evaluating the academic trend of RFID technology based on SCI and SSCI publications from 2001 to 2014. Scientometrics 1-24.

http://dx.doi.org/10.1007/s11192-016-2095-y

been made in this area where outlets such as Expert Systems with Applications (62 documents) and International Journal of Production Economics (54 documents) illustrate this trend. We are eager to see which other journals, particularly those in operations management and information systems, take up the mantle for advancing research on RFID and related emerging technologies. We also hope to see a modification of the perspective taken by funding agencies on this issues. Much funding is currently being funneled to the STEM fields of science, technology, engineering and math. While funding agencies such as the US National Science Foundation have funded some technical studies related to RFID, in general business and management issues, even when related to specific technologies such as RFID, are not considered a STEM-related area. Until information technology management is considered a STEM-related area research funding of these issues is likely to be sparse. Ultimately, though we expect to see a shift to more investigation of the management and business issues in the coming decade. Based on this discussion, the trend of RFID research has tended to stay in the technical area and we echo that suggestions made by Curtin, et al. (2007) about the need for more well-rounded RFID research agenda.

v. Our literature survey shows that about a third of the 100 most-cited articles concentrate on topics in the RFID Applications category of our framework. There are 9 different application areas shown in Fig 6 which are investigated in these documents, where Food Industry \& Agriculture, Supply Chain Management, and Retailing \& E-commerce are the most popular sub-categories with 7, 6, and 5 papers respectively. In the future, RFID is expected to be used in more applications in various locations and environments. In addition to supply chain management and health care, over the next 10 years we expect to see more investigation and publications on RFID applications where the technology is applied in many other business contexts including asset tracking, traffic and logistics systems, agricultural settings, electronic commerce, and smart products, just to mention a few. Researchers in the social sciences of management, information systems, and operations management should focus on these areas in the coming decade. In addition to the experimental methodology, this is where we expect to see more case studies, simulations, theoretical analysis, and proposed models to address adoption, usage and value in these environments. In particular, within different domains and contexts the correct business model must be examined to account for value maximization as well as control of costs of implementing the technology.

vi. Finally, we expect to see more work within our third category of Policy Issues. Management policies regarding internal adoption and usage, as well as those related to external trading partner agreements making use of RFID must be examined. How will value be allocated across the value chain? What incentives need to be provided to encourage trading partners to adopt the technology? How do network externalities impact adoption and value across the value chain? Also, for all businesses and applications security is clearly an essential issue. During the last decade, deficiencies in the technology have led to relatively low security levels in many RFID applications. Consequently, there have been fewer application studies and a large number of technical publications in this area. More recently, however, security problems have been lessened due to advances in RFID technology. The impact of a perception 
Post-Print version of: Shakiba, M., Zavvari, A., Ale Ebrahim, N., \& Singh, M. J. (2016). Evaluating the academic trend of RFID technology based on SCI and SSCI publications from 2001 to 2014. Scientometrics 1-24.

http://dx.doi.org/10.1007/s11192-016-2095-y

of lingering security problems is a social science issue that impacts adoption. On a related issue, RFID and related wireless sensor networks have the potential to threaten individual privacy which would hamper adoption in public settings. These privacy issues need to be examined from the perspective of personal information as a private good which can be exchanged given proper incentives. All of these issues must be given more attention by researchers and we hope will result in more publications in these areas in the coming decade.

It is hoped that this examination of the existing literature stream of research related to RFID technology based on current academic publications will provide a roadmap and support the future direction of research in this area. In addition, it provides a foundation on which to build new literature streams in related areas such as the internet of things, wireless sensor networks, ubiquitous computing, and automatic identification systems. 
Post-Print version of: Shakiba, M., Zavvari, A., Ale Ebrahim, N., \& Singh, M. J. (2016). Evaluating the academic trend of RFID technology based on SCI and SSCI publications from 2001 to 2014. Scientometrics 1-24.

http://dx.doi.org/10.1007/s11192-016-2095-y

\section{References}

Abad, E., Palacio, F., Nuin, M., De Zarate, A. G., Juarros, A., Gómez, J., \& Marco, S. (2009). RFID smart tag for traceability and cold chain monitoring of foods: Demonstration in an intercontinental fresh fish logistic chain. Journal of food engineering, 93(4), 394-399.

Angeles, R. (2005). RFID technologies: supply-chain applications and implementation issues. Information Systems Management, 22(1), 51-65.

Atzori, L., Iera, A., \& Morabito, G. (2010). The internet of things: A survey. Computer networks, 54(15), $2787-$ 2805.

Baeg, K. J., Caironi, M., \& Noh, Y. Y. (2013). Toward printed integrated circuits based on unipolar or ambipolar polymer semiconductors. Advanced Materials, 25(31), 4210-4244.

Baude, P., Ender, D., Haase, M., Kelley, T., Muyres, D., \& Theiss, S. (2003). Pentacene-based radio-frequency identification circuitry. Applied Physics Letters, 82(22), 3964-3966.

Bhuptani, M., \& Moradpour, S. (2005). RFID field guide: deploying radio frequency identification systems: Prentice Hall PTR.

Bottani, E., \& Rizzi, A. (2008). Economical assessment of the impact of RFID technology and EPC system on the fast-moving consumer goods supply chain. International Journal of Production Economics, 112(2), 548-569.

Cantatore, E., Geuns, T. C., Gelinck, G. H., van Veenendaal, E., Gruijthuijsen, A. F., Schrijnemakers, L., . . . de Leeuw, D. M. (2007). A 13.56-MHz RFID system based on organic transponders. Solid-State Circuits, IEEE Journal of, 42(1), 84-92.

Cattuto, C., Van den Broeck, W., Barrat, A., Colizza, V., Pinton, J.-F., \& Vespignani, A. (2010). Dynamics of person-to-person interactions from distributed RFID sensor networks. PloS one, 5(7), e11596.

Chao, C.-C., Yang, J.-M., \& Jen, W.-Y. (2007). Determining technology trends and forecasts of RFID by a historical review and bibliometric analysis from 1991 to 2005. Technovation, 27(5), 268-279.

Chen, W.-T. (2009). An accurate tag estimate method for improving the performance of an RFID anticollision algorithm based on dynamic frame length ALOHA. Automation Science and Engineering, IEEE Transactions on, 6(1), 9-15.

Chien, H.-Y. (2007). SASI: A new ultralightweight RFID authentication protocol providing strong authentication and strong integrity. Dependable and Secure Computing, IEEE Transactions on, 4(4), 337-340.

Chien, H.-Y., \& Chen, C.-H. (2007). Mutual authentication protocol for RFID conforming to EPC Class 1 Generation 2 standards. Computer Standards \& Interfaces, 29(2), 254-259.

Chow, H. K., Choy, K. L., Lee, W., \& Lau, K. (2006). Design of a RFID case-based resource management system for warehouse operations. Expert Systems with Applications, 30(4), 561-576.

Chu, H.-C., Hwang, G.-J., Tsai, C.-C., \& Tseng, J. C. (2010). A two-tier test approach to developing locationaware mobile learning systems for natural science courses. Computers \& Education, 55(4), 1618-1627.

Couto, F. M., Grego, T., Pesquita, C., \& Verissimo, P. (2009). Handling self-citations using Google Scholar.

Curtin, J., Kauffman, R. J., \& Riggins, F. J. (2007). Making the MOST'out of RFID technology: a research agenda for the study of the adoption, usage and impact of RFID. Information Technology and Management, 8(2), 87-110.

Curty, J.-P., Joehl, N., Dehollaini, C., \& Declercq, M. J. (2005). Remotely powered addressable UHF RFID integrated system. Solid-State Circuits, IEEE Journal of, 40(11), 2193-2202.

De Vita, G., \& Iannaccone, G. (2005). Design criteria for the RF section of UHF and microwave passive RFID transponders. Microwave Theory and Techniques, IEEE Transactions on, 53(9), 2978-2990.

Delen, D., Hardgrave, B. C., \& Sharda, R. (2007). RFID for Better Supply-Chain Management through Enhanced Information Visibility. Production and operations management, 16(5), 613-624.

DiGiampaolo, E., \& Martinelli, F. (2014). Mobile robot localization using the phase of passive UHF RFID signals. Industrial Electronics, IEEE Transactions on, 61(1), 365-376.

Dodabalapur, A. (2006). Organic and polymer transistors for electronics. Materials Today, 9(4), 24-30.

Feldhofer, M., Dominikus, S., \& Wolkerstorfer, J. (2004). Strong authentication for RFID systems using the AES algorithm Cryptographic Hardware and Embedded Systems-CHES 2004 (pp. 357-370): Springer.

Fortunato, E., Correia, N., Barquinha, P., Pereira, L., Gonçalves, G., \& Martins, R. (2008). High-performance flexible hybrid field-effect transistors based on cellulose fiber paper. Electron Device Letters, IEEE, 29(9), 988-990.

Fosso Wamba, S., Lefebvre, L. A., Bendavid, Y., \& Lefebvre, É. (2008). Exploring the impact of RFID technology and the EPC network on mobile B2B eCommerce: A case study in the retail industry. International Journal of Production Economics, 112(2), 614-629.

Garfinkel, S. L., Juels, A., \& Pappu, R. (2005). RFID privacy: An overview of problems and proposed solutions. 
Post-Print version of: Shakiba, M., Zavvari, A., Ale Ebrahim, N., \& Singh, M. J. (2016). Evaluating the academic trend of RFID technology based on SCI and SSCI publications from 2001 to 2014. Scientometrics 1-24.

http://dx.doi.org/10.1007/s11192-016-2095-y

Gaukler, G. M., Seifert, R. W., \& Hausman, W. H. (2007). Item-Level RFID in the Retail Supply Chain. Production and operations management, 16(1), 65-76.

Gubbi, J., Buyya, R., Marusic, S., \& Palaniswami, M. (2013). Internet of Things (IoT): A vision, architectural elements, and future directions. Future Generation Computer Systems, 29(7), 1645-1660.

He, W., \& Da Xu, L. (2014). Integration of distributed enterprise applications: a survey. Industrial Informatics, IEEE Transactions on, 10(1), 35-42.

Heinrich, C. (2005). RFID and beyond: growing your business through real world awareness: Wiley.

Henry, M., Beguin, M., Requier, F., Rollin, O., Odoux, J.-F., Aupinel, P., . . Decourtye, A. (2012). A common pesticide decreases foraging success and survival in honey bees. Science, 336(6079), 348-350.

Hirsch, J. E. (2005). An index to quantify an individual's scientific research output. Proceedings of the National academy of Sciences of the United States of America, 102(46), 16569-16572.

Hong, D., Sung, J., Hong, S., Lim, J., Lee, S., Koo, B.-S., . . Jeong, K. (2006). HIGHT: A new block cipher suitable for low-resource device Cryptographic Hardware and Embedded Systems-CHES 2006 (pp. 4659): Springer.

Huang, D., Liao, F., Molesa, S., Redinger, D., \& Subramanian, V. (2003). Plastic-compatible low resistance printable gold nanoparticle conductors for flexible electronics. Journal of the electrochemical society, 150(7), G412-G417.

Jara, A. J., Zamora, M. A., \& Skarmeta, A. F. (2011). An internet of things---based personal device for diabetes therapy management in ambient assisted living (AAL). Personal and Ubiquitous Computing, 15(4), 431-440.

Juels, A. (2006). RFID security and privacy: A research survey. Selected Areas in Communications, IEEE Journal on, 24(2), 381-394.

Juels, A., \& Weis, S. A. (2005). Authenticating pervasive devices with human protocols. Paper presented at the Advances in Cryptology-CRYPTO 2005.

Jung, M., Kim, J., Noh, J., Lim, N., Lim, C., Lee, G., . . Leonard, A. D. (2010). All-printed and roll-to-rollprintable 13.56-MHz-operated 1-bit RF tag on plastic foils. Electron Devices, IEEE Transactions on, 57(3), 571-580.

Kahhat, R., Kim, J., Xu, M., Allenby, B., Williams, E., \& Zhang, P. (2008). Exploring e-waste management systems in the United States. Resources, Conservation and Recycling, 52(7), 955-964.

Kamyshny, A., \& Magdassi, S. (2014). Conductive nanomaterials for printed electronics. Small, 10(17), 3515 3535 .

Karthaus, U., \& Fischer, M. (2003). Fully integrated passive UHF RFID transponder IC with 16.7-mu W minimum RF input power. IEEE JOURNAL OF SOLID-STATE CIRCUITS, 38(10), 1602-1608.

Kerry, J., O'grady, M., \& Hogan, S. (2006). Past, current and potential utilisation of active and intelligent packaging systems for meat and muscle-based products: A review. Meat science, 74(1), 113-130.

Kiani, M., \& Ghovanloo, M. (2012). The circuit theory behind coupled-mode magnetic resonance-based wireless power transmission. Circuits and Systems I: Regular Papers, IEEE Transactions on, 59(9), 2065-2074.

Klauk, H., Zschieschang, U., Pflaum, J., \& Halik, M. (2007). Ultralow-power organic complementary circuits. Nature, 445(7129), 745-748.

Knospe, H., \& Pohl, H. (2004). RFID security. Information Security Technical Report, 9(4), 39-50.

Le, T., Mayaram, K., \& Fiez, T. (2008). Efficient far-field radio frequency energy harvesting for passively powered sensor networks. Solid-State Circuits, IEEE Journal of, 43(5), 1287-1302.

Lee, H., \& Özer, Ö. (2007). Unlocking the value of RFID. Production and operations management, 16(1), 4064.

Lee, W., Alchanatis, V., Yang, C., Hirafuji, M., Moshou, D., \& Li, C. (2010). Sensing technologies for precision specialty crop production. Computers and electronics in agriculture, 74(1), 2-33.

Leong, W. L., Mathews, N., Tan, B., Vaidyanathan, S., Dötz, F., \& Mhaisalkar, S. (2011). Towards printable organic thin film transistor based flash memory devices. Journal of Materials Chemistry, 21(14), 5203 5214.

Li, L. (2013). Technology designed to combat fakes in the global supply chain. Business Horizons, 56(2), $167-$ 177.

LináWang, Z. (2013). A paper-based nanogenerator as a power source and active sensor. Energy \& Environmental Science, 6(6), 1779-1784.

Liu, X., Long, Y.-Z., Liao, L., Duan, X., \& Fan, Z. (2012). Large-scale integration of semiconductor nanowires for high-performance flexible electronics. ACS nano, 6(3), 1888-1900.

Logothetidis, S. (2008). Flexible organic electronic devices: Materials, process and applications. Materials Science and Engineering: B, 152(1), 96-104.

Luechinger, N. A., Athanassiou, E. K., \& Stark, W. J. (2008). Graphene-stabilized copper nanoparticles as an air-stable substitute for silver and gold in low-cost ink-jet printable electronics. Nanotechnology, 19(44), 445201. 
Post-Print version of: Shakiba, M., Zavvari, A., Ale Ebrahim, N., \& Singh, M. J. (2016). Evaluating the academic trend of RFID technology based on SCI and SSCI publications from 2001 to 2014. Scientometrics 1-24.

http://dx.doi.org/10.1007/s11192-016-2095-y

Magdassi, S., Grouchko, M., \& Kamyshny, A. (2010). Copper nanoparticles for printed electronics: routes towards achieving oxidation stability. Materials, 3(9), 4626-4638.

Mandal, S., \& Sarpeshkar, R. (2007). Low-power CMOS rectifier design for RFID applications. Circuits and Systems I: Regular Papers, IEEE Transactions on, 54(6), 1177-1188.

Marrocco, G. (2008). The art of UHF RFID antenna design: impedance-matching and size-reduction techniques. Antennas and Propagation Magazine, IEEE, 50(1), 66-79.

Meyer, G. G., Främling, K., \& Holmström, J. (2009). Intelligent products: A survey. Computers in Industry, 60(3), 137-148.

Miorandi, D., Sicari, S., De Pellegrini, F., \& Chlamtac, I. (2012). Internet of things: Vision, applications and research challenges. Ad Hoc Networks, 10(7), 1497-1516.

Myny, K., Steudel, S., Smout, S., Vicca, P., Furthner, F., van der Putten, B., . . Dehaene, W. (2010). Organic RFID transponder chip with data rate compatible with electronic product coding. Organic Electronics, 11(7), 1176-1179.

Myung, J., Lee, W., \& Srivastava, J. (2006). Adaptive binary splitting for efficient RFID tag anti-collision. IEEE Communications Letters, 10(3), 144-146.

Ngai, E., Moon, K. K., Riggins, F. J., \& Yi, C. Y. (2008). RFID research: An academic literature review (19952005) and future research directions. International Journal of Production Economics, 112(2), 510-520.

Ngai, E. W., Cheng, T. E., Au, S., \& Lai, K.-h. (2007). Mobile commerce integrated with RFID technology in a container depot. Decision Support Systems, 43(1), 62-76.

Ni, L. M., Liu, Y., Lau, Y. C., \& Patil, A. P. (2004). LANDMARC: indoor location sensing using active RFID. Wireless networks, 10(6), 701-710.

Nikitin, P. V., \& Rao, K. S. (2006). Theory and measurement of backscattering from RFID tags. Antennas and Propagation Magazine, IEEE, 48(6), 212-218.

Nikitin, P. V., Rao, K. S., Lam, S. F., Pillai, V., Martinez, R., \& Heinrich, H. (2005). Power reflection coefficient analysis for complex impedances in RFID tag design. IEEE Transactions on Microwave Theory and Techniques, 53(9), 2721-2725.

Panda, J. R., \& Kshetrimayum, R. S. (2011). A PRINTED 2.4 GHZ/5.8 GHZ DUAL-BAND MONOPOLE ANTENNA WITH A PROTRUDING STUB IN THE GROUND PLANE FOR WLAN AND RFID APPLICATIONS. Progress In Electromagnetics Research, 117.

Park, S., Vosguerichian, M., \& Bao, Z. (2013). A review of fabrication and applications of carbon nanotube film-based flexible electronics. Nanoscale, 5(5), 1727-1752.

Preradovic, S., Balbin, I., Karmakar, N. C., \& Swiegers, G. F. (2009). Multiresonator-based chipless RFID system for low-cost item tracking. Microwave Theory and Techniques, IEEE Transactions on, 57(5), 1411-1419.

Preradovic, S., \& Karmakar, N. C. (2010). Chipless RFID: bar code of the future. Microwave Magazine, IEEE, 11(7), 87-97.

Rao, K. S., Nikitin, P. V., \& Lam, S. F. (2005). Antenna design for UHF RFID tags: A review and a practical application. Antennas and Propagation, IEEE Transactions on, 53(12), 3870-3876.

Regattieri, A., Gamberi, M., \& Manzini, R. (2007). Traceability of food products: General framework and experimental evidence. Journal of food engineering, 81(2), 347-356.

The Thomson Reuters Impact Factor, (2010).

Rida, A., Yang, L., Vyas, R., \& Tentzeris, M. M. (2009). Conductive inkjet-printed antennas on flexible low-cost paper-based substrates for RFID and WSN applications. Antennas and Propagation Magazine, IEEE, $51(3), 13-23$.

Roberts, C. M. (2006). Radio frequency identification (RFID). Computers \& Security, 25(1), 18-26.

Rotzoll, R., Mohapatra, S., Olariu, V., Wenz, R., Grigas, M., Dimmler, K., . . Dodabalapur, A. (2006). Radio frequency rectifiers based on organic thin-film transistors. Applied Physics Letters, 88(12), 123502123502-123503.

Ruiz-Garcia, L., Lunadei, L., Barreiro, P., \& Robla, I. (2009). A review of wireless sensor technologies and applications in agriculture and food industry: state of the art and current trends. Sensors, 9(6), 47284750.

Ruiz, A. R. J., Granja, F. S., Prieto Honorato, J. C., \& Rosas, J. I. G. (2012). Accurate pedestrian indoor navigation by tightly coupling foot-mounted IMU and RFID measurements. Instrumentation and Measurement, IEEE Transactions on, 61(1), 178-189.

Sample, A. P., Yeager, D. J., Powledge, P. S., Mamishev, A. V., \& Smith, J. R. (2008). Design of an RFIDbased battery-free programmable sensing platform. Instrumentation and Measurement, IEEE Transactions on, 57(11), 2608-2615.

Sarac, A., Absi, N., \& Dauzère-Pérès, S. (2010). A literature review on the impact of RFID technologies on supply chain management. International Journal of Production Economics, 128(1), 77-95. 
Post-Print version of: Shakiba, M., Zavvari, A., Ale Ebrahim, N., \& Singh, M. J. (2016). Evaluating the academic trend of RFID technology based on SCI and SSCI publications from 2001 to 2014. Scientometrics 1-24.

http://dx.doi.org/10.1007/s11192-016-2095-y

Sarma, S. E., Weis, S. A., \& Engels, D. W. (2003). RFID systems and security and privacy implications Cryptographic Hardware and Embedded Systems-CHES 2002 (pp. 454-469): Springer.

Sauer, M., Kobyakov, A., \& George, J. (2007). Radio over fiber for picocellular network architectures. Journal of Lightwave Technology, 25(11), 3301-3320.

Schneider, C. W., Tautz, J., Grünewald, B., \& Fuchs, S. (2012). RFID tracking of sublethal effects of two neonicotinoid insecticides on the foraging behavior of Apis mellifera. PloS one, 7(1), e30023.

Shakiba, M., Singh, M. J., Sundararajan, E., Zavvari, A., \& Islam, M. T. (2014). Extending Birthday Paradox Theory to Estimate the Number of Tags in RFID Systems. PloS one, 9(4), e95425.

Shakiba, M., Sundararajan, E., Zavvari, A., \& Islam, M. (2013). Cubic spline-based tag estimation method in RFID multi-tags identification process. Electrical and Computer Engineering, Canadian Journal of, 36(1), 11-17.

Shih, D.-H., Sun, P.-L., Yen, D. C., \& Huang, S.-M. (2006). Taxonomy and survey of RFID anti-collision protocols. Computer communications, 29(11), 2150-2166.

Stehlé, J., Voirin, N., Barrat, A., Cattuto, C., Colizza, V., Isella, L., . . V Van den Broeck, W. (2011). Simulation of an SEIR infectious disease model on the dynamic contact network of conference attendees. BMC medicine, 9(1), 87.

Stehlé, J., Voirin, N., Barrat, A., Cattuto, C., Isella, L., Pinton, J.-F., . . Lina, B. (2011). High-resolution measurements of face-to-face contact patterns in a primary school. PloS one, 6(8), e23176.

Steudel, S., Myny, K., Arkhipov, V., Deibel, C., De Vusser, S., Genoe, J., \& Heremans, P. (2005). 50 MHz rectifier based on an organic diode. Nature materials, 4(8), 597-600.

Subramanian, V., Chang, P. C., Lee, J. B., Molesa, S. E., \& Volkman, S. K. (2005). Printed organic transistors for ultra-low-cost RFID applications. Components and Packaging Technologies, IEEE Transactions on, 28(4), 742-747.

Subramanian, V., Fréchet, J. M., Chang, P. C., Huang, D. C., Lee, J. B., Molesa, S. E., . . Volkman, S. K. (2005). Progress toward development of all-printed RFID tags: materials, processes, and devices. Proceedings of the IEEE, 93(7), 1330-1338.

Sun, J., Zhang, B., \& Katz, H. E. (2011). Materials for Printable, Transparent, and Low-Voltage Transistors. Advanced Functional Materials, 21(1), 29-45.

Symonds, J., Ayoade, J., \& Parry, D. (2009). Auto-Identification and ubiquitous computing applications: USA: Information Science Reference.

Tiang, J.-J., Islam, M. T., Misran, N., \& Mandeep, J. S. (2011). CIRCULAR MICROSTRIP SLOT ANTENNA FOR DUAL-FREQUENCY RFID APPLICATION. Progress In Electromagnetics Research, 120.

Tzeng, S.-F., Chen, W.-H., \& Pai, F.-Y. (2008). Evaluating the business value of RFID: evidence from five case studies. International Journal of Production Economics, 112(2), 601-613.

Umeda, T., Yoshida, H., Sekine, S., Fujita, Y., Suzuki, T., \& Otaka, S. (2006). A 950-MHz rectifier circuit for sensor network tags with 10-m distance. Solid-State Circuits, IEEE Journal of, 41(1), 35-41.

Usta, H., Facchetti, A., \& Marks, T. J. (2011). n-Channel semiconductor materials design for organic complementary circuits. Accounts of chemical research, 44(7), 501-510.

Van Der Togt, R., van Lieshout, E. J., Hensbroek, R., Beinat, E., Binnekade, J., \& Bakker, P. (2008). Electromagnetic interference from radio frequency identification inducing potentially hazardous incidents in critical care medical equipment. Jama, 299(24), 2884-2890.

Wang, L., Da Xu, L., Bi, Z., \& Xu, Y. (2014). Data cleaning for RFID and WSN integration. Industrial Informatics, IEEE Transactions on, 10(1), 408-418.

Wang, N., Zhang, N., \& Wang, M. (2006). Wireless sensors in agriculture and food industry-Recent development and future perspective. Computers and electronics in agriculture, 50(1), 1-14.

Want, R. (2006). An introduction to RFID technology. Pervasive Computing, IEEE, 5(1), 25-33.

Weis, S. A., Sarma, S. E., Rivest, R. L., \& Engels, D. W. (2004). Security and privacy aspects of low-cost radio frequency identification systems Security in pervasive computing (pp. 201-212): Springer.

Welbourne, E., Battle, L., Cole, G., Gould, K., Rector, K., Raymer, S., . . Borriello, G. (2009). Building the internet of things using RFID: the RFID ecosystem experience. Internet Computing, IEEE, 13(3), 4855.

Wu, N.-C., Nystrom, M., Lin, T.-R., \& Yu, H.-C. (2006). Challenges to global RFID adoption. Technovation, 26(12), 1317-1323.

Xu, L. D. (2011). Information architecture for supply chain quality management. International Journal of Production Research, 49(1), 183-198.

Yang, C., Gu, H., Lin, W., Yuen, M. M., Wong, C. P., Xiong, M., \& Gao, B. (2011). Silver nanowires: from scalable synthesis to recyclable foldable electronics. Advanced Materials, 23(27), 3052-3056.

Yang, L., Rida, A., Vyas, R., \& Tentzeris, M. M. (2007). RFID tag and RF structures on a paper substrate using inkjet-printing technology. Microwave Theory and Techniques, IEEE Transactions on, 55(12), 28942901. 
Post-Print version of: Shakiba, M., Zavvari, A., Ale Ebrahim, N., \& Singh, M. J. (2016). Evaluating the academic trend of RFID technology based on SCI and SSCI publications from 2001 to 2014. Scientometrics 1-24.

http://dx.doi.org/10.1007/s11192-016-2095-y

Yang, L., Zhang, R., Staiculescu, D., Wong, C., \& Tentzeris, M. M. (2009). A novel conformal RFID-enabled module utilizing inkjet-printed antennas and carbon nanotubes for gas-detection applications. Antennas and Wireless Propagation Letters, IEEE, 8, 653-656.

Zhou, G., Li, F., \& Cheng, H.-M. (2014). Progress in flexible lithium batteries and future prospects. Energy \& Environmental Science, 7(4), 1307-1338.

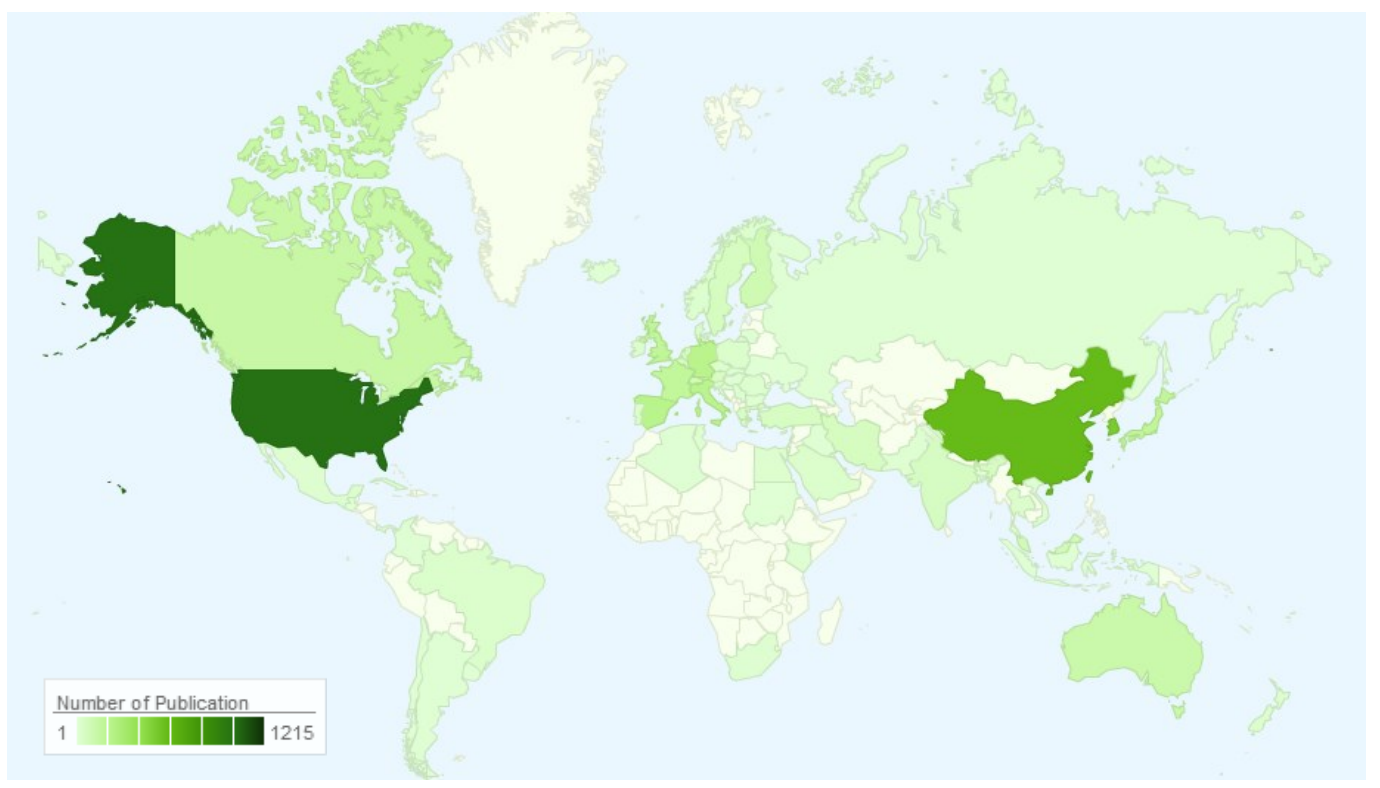

Fig 1. RFID Map: contribution of different countries with RFID technology, based on number of publications

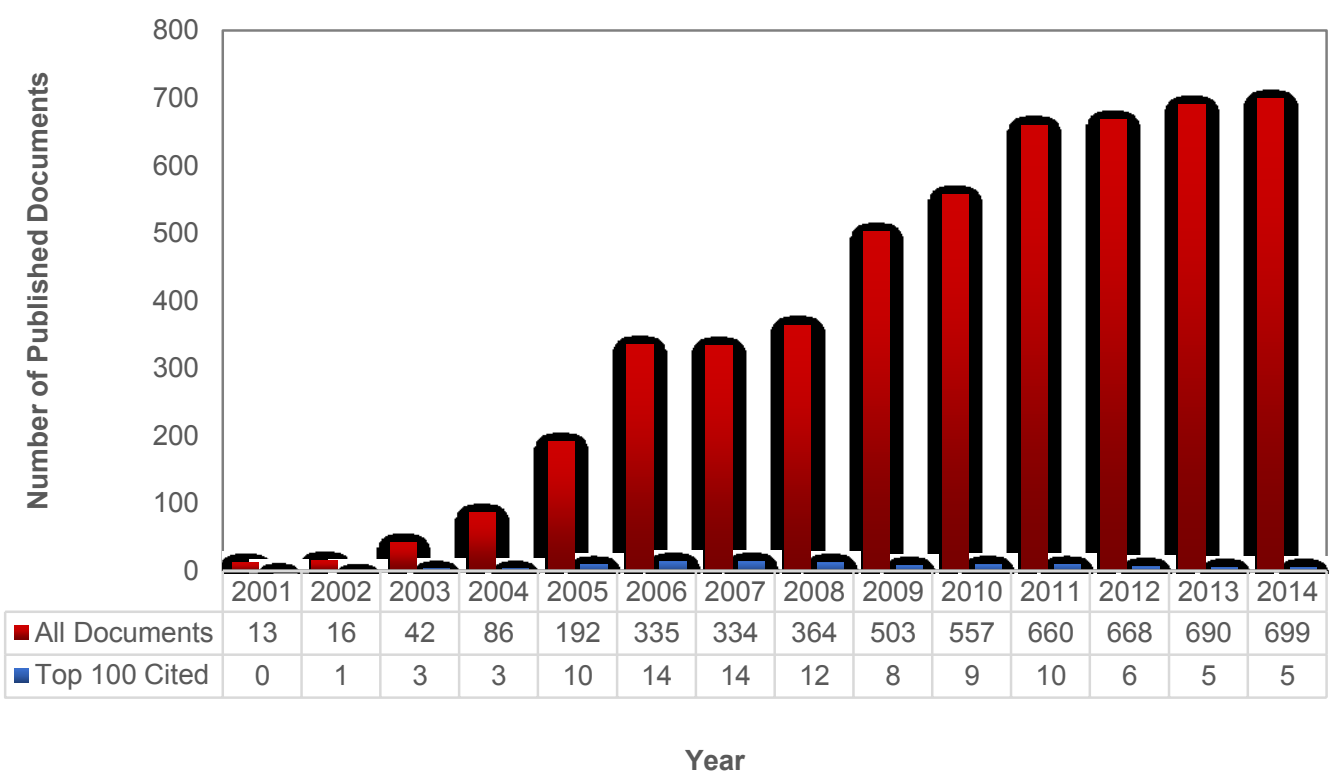

Fig 2. Distribution by publication year from 2001 to 2014 
Post-Print version of: Shakiba, M., Zavvari, A., Ale Ebrahim, N., \& Singh, M. J. (2016). Evaluating the academic trend of RFID technology based on SCI and SSCI publications from 2001 to 2014. Scientometrics 1-24. http://dx.doi.org/10.1007/s11192-016-2095-y

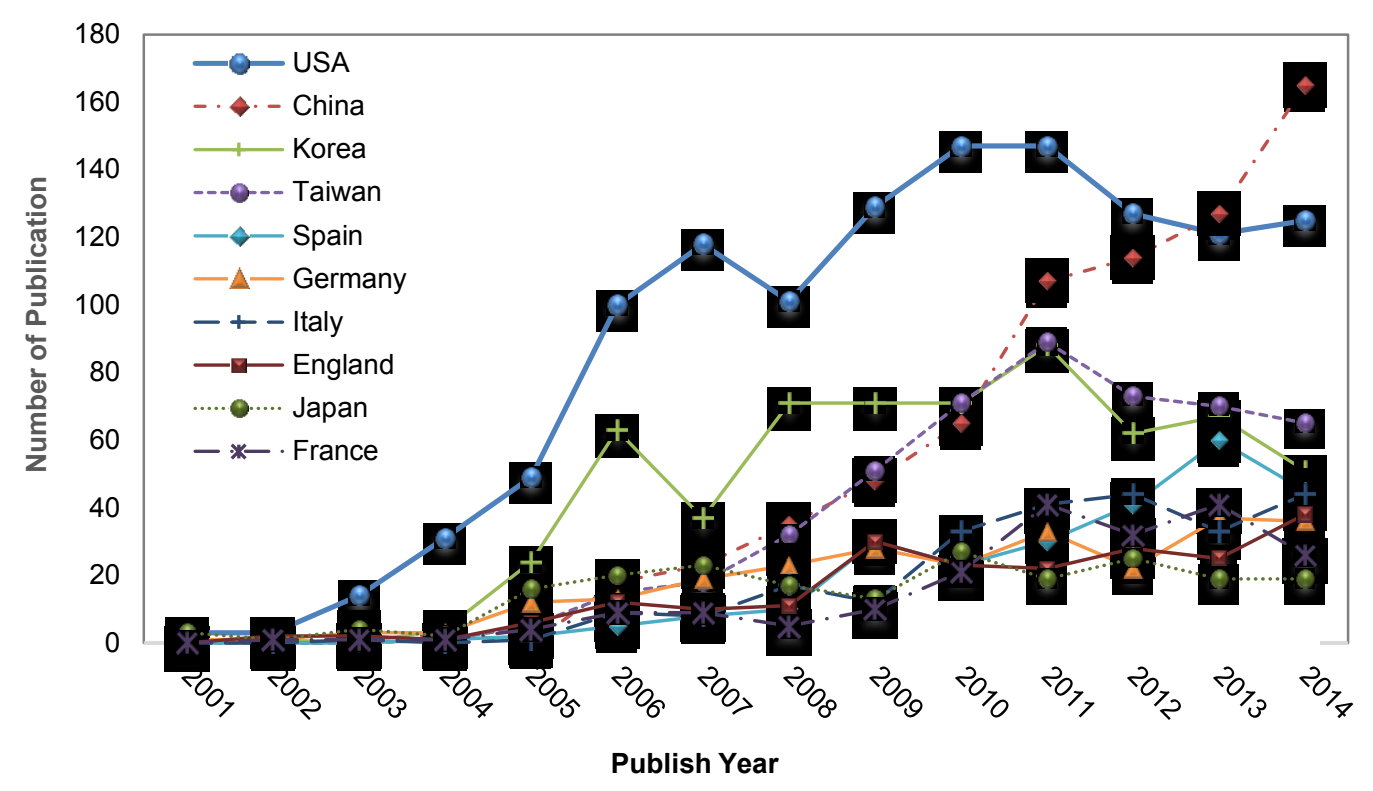

Fig 3. Distribution by publication year from 2001 to 2014 for top 10 countries

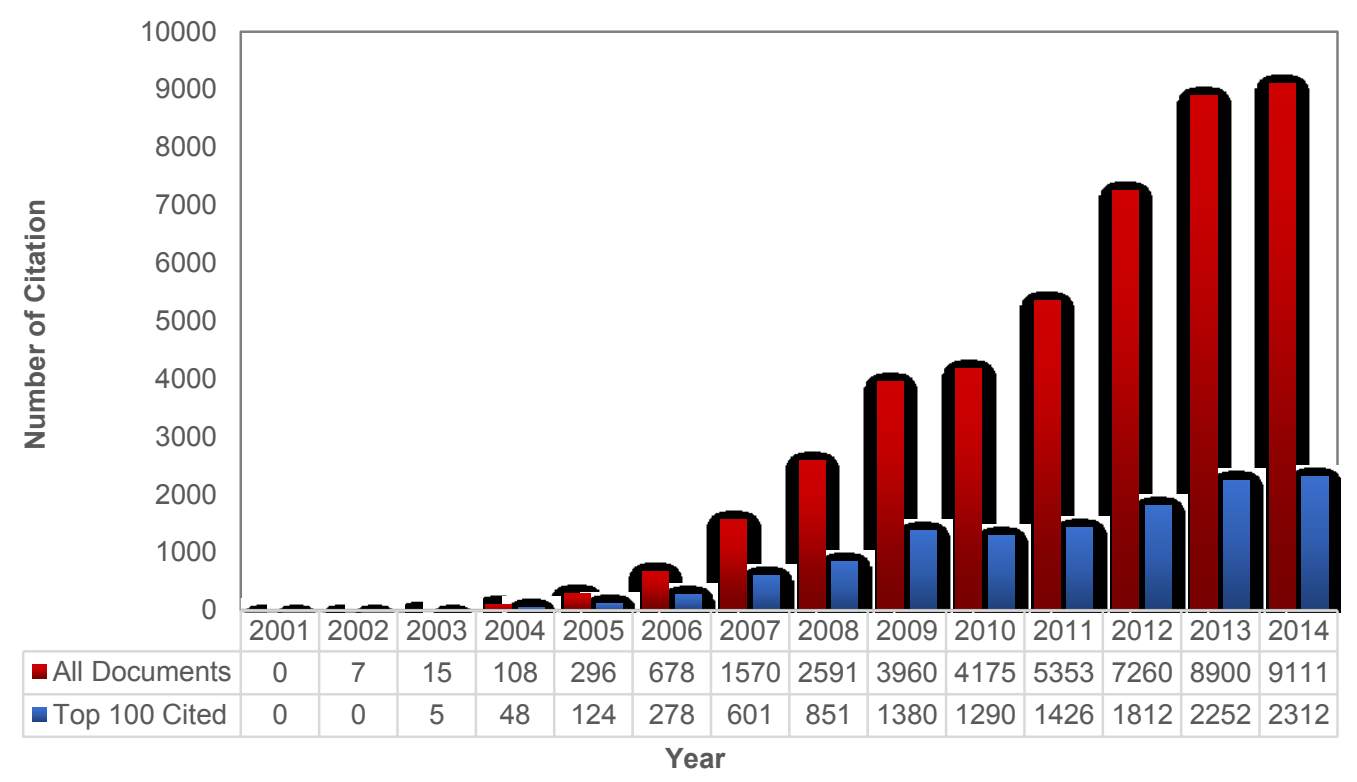

Fig 4. Distribution by citation per year from 2001 to 2014 
Post-Print version of: Shakiba, M., Zavvari, A., Ale Ebrahim, N., \& Singh, M. J. (2016). Evaluating the academic trend of RFID technology based on SCI and SSCI publications from 2001 to 2014. Scientometrics 1-24.

http://dx.doi.org/10.1007/s11192-016-2095-y

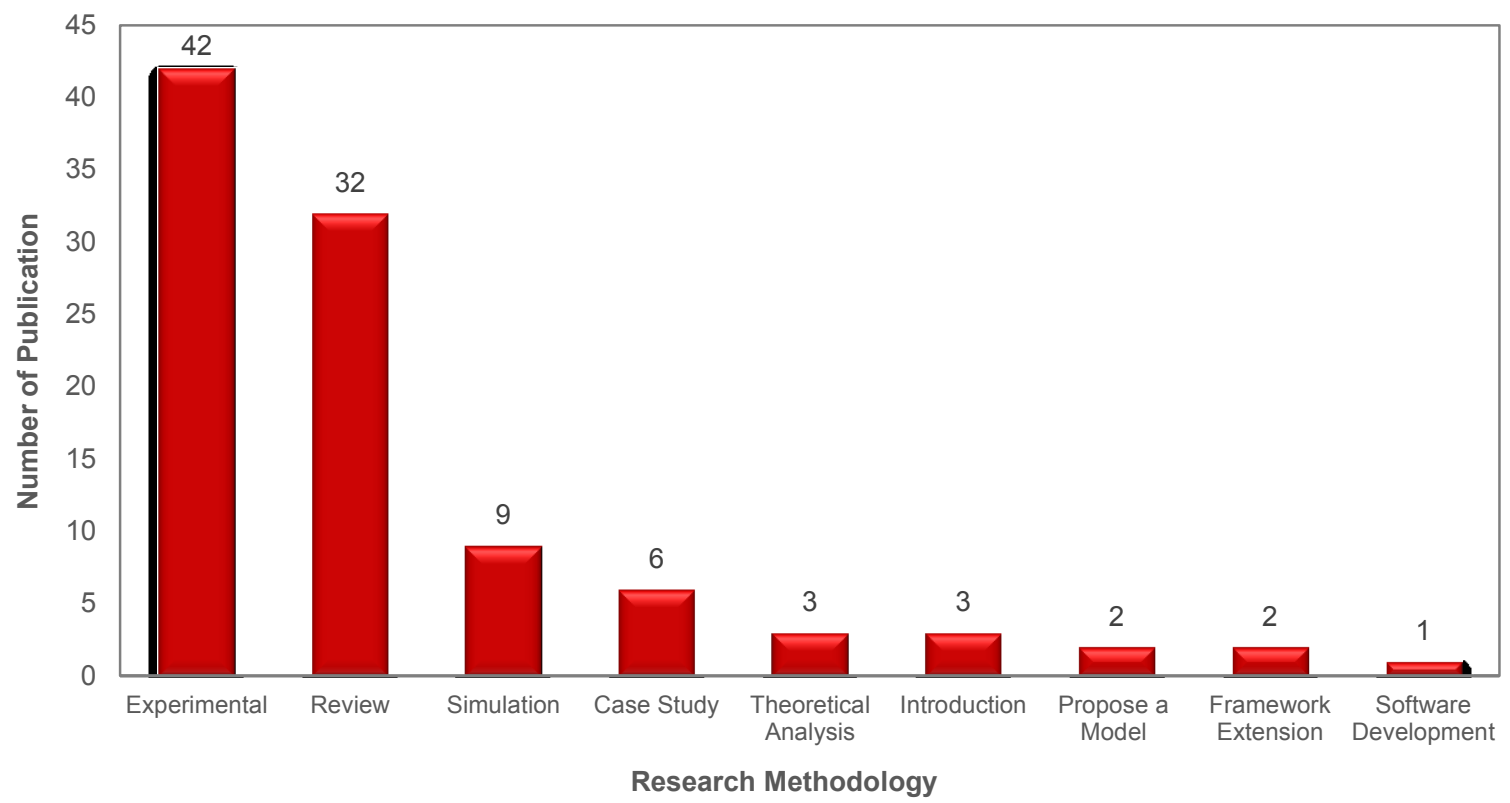

Fig 5. Frequency of nine research methodologies across the top most cited 100 papers in RFID

Table 1. Times cited for nine different research methodologies

\begin{tabular}{lrrr}
\hline Methodology & NP & TC & Avg. TC \\
\hline Experimental & 42 & 5503 & 131.02 \\
Review & 32 & 4543 & 141.97 \\
Simulation & 9 & 939 & 104.33 \\
Case Study & 6 & 512 & 85.33 \\
Theoretical Analysis & 3 & 329 & 109.67 \\
Introduction & 3 & 293 & 97.67 \\
Propose a Model & 2 & 376 & 188 \\
Framework Extension & 2 & 146 & 73 \\
Software Development & 1 & 93 & 93 \\
\hline Grand Total & 100 & 12734 & 127.34
\end{tabular}

NP: Number of Publication

TC: Time Cited

Avg. TC: Average Time Cited per Document 
Post-Print version of: Shakiba, M., Zavvari, A., Ale Ebrahim, N., \& Singh, M. J. (2016). Evaluating the academic trend of RFID technology based on SCI and SSCI publications from 2001 to 2014. Scientometrics 1-24.

http://dx.doi.org/10.1007/s11192-016-2095-y

Table 2. Times cited for four different subject categories

\begin{tabular}{lrrr}
\hline Category & NP & TC & Avg. TC \\
\hline RFID Technology & 36 & 5,590 & 155.28 \\
RFID Applications & 33 & 2,822 & 85.52 \\
Policy Issues & 8 & 1,477 & 184.63 \\
Others & 23 & 2,845 & 123.7 \\
\hline Sum & 100 & 10,803 & 108.03 \\
\hline
\end{tabular}

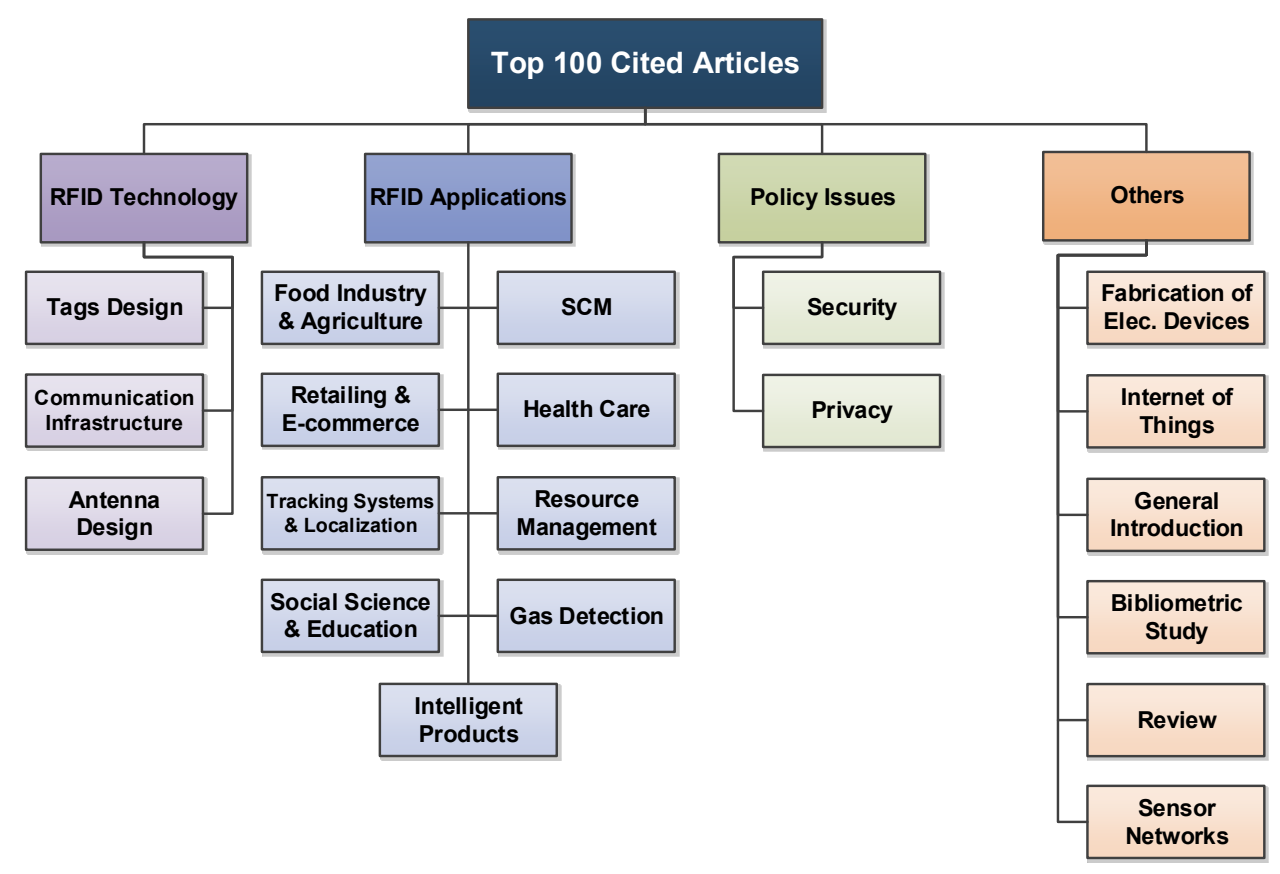

Fig 6. Classification of top 100 RFID papers based on the subject of study

Table 3. Publications in the RFID Technology sub-categories

\begin{tabular}{lcccr}
\hline RFID Technology Sub-Categories & NP & \% by Category & TC & Avg. TC \\
\hline Tags Design and Fabrication & 21 & 58.33 & 3780 & 180 \\
Communication infrastructure & 8 & 22.22 & 934 & 116.75 \\
Antenna Design & 7 & 19.45 & 876 & 125.14 \\
\hline Sum & 36 & 100 & 5590 & 155.28 \\
\hline
\end{tabular}


Post-Print version of: Shakiba, M., Zavvari, A., Ale Ebrahim, N., \& Singh, M. J. (2016). Evaluating the academic trend of RFID technology based on SCI and SSCI publications from 2001 to 2014. Scientometrics 1-24.

http://dx.doi.org/10.1007/s11192-016-2095-y

Table 4. RFID Applications sub-categories publication number

\begin{tabular}{lcccc}
\hline RFID App Sub-Categories & NP & \% by Category & TC & Avg. TC \\
\hline Food Industry \& Agriculture & 7 & 21.21 & 876 & 125.14 \\
Supply Chain Management & 6 & 18.19 & 628 & 104.67 \\
Retail Business \& E-commerce & 5 & 15.15 & 360 & 72 \\
Health Care & 4 & 12.12 & 252 & 63 \\
Tracking System \& Localization & 3 & 9.09 & 106 & 35.33 \\
Resource Management & 3 & 9.09 & 275 & 91.67 \\
Social Science \& Education & 3 & 9.09 & 198 & 66 \\
Gas Detection & 1 & 3.03 & 61 & 61 \\
Intelligent Products & 1 & 3.03 & 66 & 66 \\
\hline Sum & 33 & 100 & 2822 & 85.52 \\
\hline
\end{tabular}

Table 5. Policy issues sub-categories publication number

\begin{tabular}{lcccr}
\hline Policy Issues Sub-Categories & NP & \% at Category & TC & Avg. TC \\
\hline Security & 6 & 75 & 955 & 159.17 \\
Privacy & 2 & 25 & 522 & 261 \\
\hline Sum & 8 & 100 & 1477 & 184.63 \\
\hline
\end{tabular}

Table 6. Others subjects sub-categories publication number

\begin{tabular}{lcccc}
\hline Others Sub-Categories & NP & \% at Category & TC & Avg. TC \\
\hline Fabrication of Electronic Devices & 10 & 43.49 & 781 & 78.1 \\
Internet of Things & 3 & 13.04 & 673 & 224.33 \\
General Introduction & 3 & 13.04 & 586 & 195.33 \\
Bibliometric Study & 3 & 13.04 & 357 & 119 \\
Review & 3 & 13.04 & 343 & 114.33 \\
Sensor Networks & 1 & 4.35 & 105 & 105 \\
\hline Sum & 23 & 100 & 2845 & 123.7 \\
\hline
\end{tabular}


Table 7. Classification of the reviewed literature

\begin{tabular}{ll}
\hline Classification & References \\
\hline RFID Technology &
\end{tabular}

Tags Design and Fabrication

\section{Communication infrastructure}

Antenna Design

\section{RFID Applications}

Food Industry \& Agriculture

SCM

\author{
Retailing \& \\ E-commerce
}

(Klauk, Zschieschang, Pflaum, \& Halik, 2007), 700, 87.5; (Usta, Facchetti, \& Marks, 2011), 228, 57; (Zhou, Li, \& Cheng, 2014), 47, 47; (Baude et al., 2003), 531, 44.25; (Baeg, Caironi, \& Noh, 2013), 66, 33; (Karthaus \& Fischer, 2003), 371, 30.92; (Cantatore et al., 2007), 205, 25.625; (Jung et al., 2010), 122, 24.4; (Subramanian, Fréchet, et al., 2005), 230, 23; (L. Yang, Rida, Vyas, \& Tentzeris, 2007), 181, 22.625; (De Vita \& Iannaccone, 2005), 171, 17.1; (Myny et al., 2010), 85, 17; (Curty, Joehl, Dehollaini, \& Declercq, 2005), 153, 15.3; (C. Yang et al., 2011), 58, 14.5; (Steudel et al., 2005), 135, 13.5; (Rotzoll et al., 2006), 110, 12.22; (Umeda et al., 2006), 109, 12.11; (Rida, Yang, Vyas, \& Tentzeris, 2009), 72, 12; (Subramanian, Chang, Lee, Molesa, \& Volkman, 2005), 117, 11.7; (Preradovic, Balbin, Karmakar, \& Swiegers, 2009), 68, 11.33; (LináWang, 2013), 21, 10.5.

(Ni, Liu, Lau, \& Patil, 2004), 315, 28.64; (Sample, Yeager, Powledge, Mamishev, \& Smith, 2008), 112, 16; (Sauer, Kobyakov, \& George, 2007), 123, 15.375; (Nikitin \& Rao, 2006), 130, 14.44; (L. Wang, Da Xu, Bi, \& $\mathrm{Xu}, 2014), 11,11$; (Chen, 2009), 61, 10.17; (Shih, Sun, Yen, \& Huang, 2006), 91, 10.11; (Myung, Lee, \& Srivastava, 2006), 91, 10.11.

(Rao, Nikitin, \& Lam, 2005), 367, 36.7; (Marrocco, 2008), 177, 25.29; (Nikitin et al., 2005), 130, 13; (Kiani \& Ghovanloo, 2012), 34, 11.33; (Panda \& Kshetrimayum, 2011), 43, 10.75; (Tiang, Islam, Misran, \& Mandeep, 2011), 42, 10.5; (Mandal \& Sarpeshkar, 2007), 83, 10.375.

(Henry et al., 2012), 156, 52; (N. Wang, Zhang, \& Wang, 2006), 238, 26.44; (Regattieri, Gamberi, \& Manzini, 2007), 133, 16.22; (Kerry, O'grady, \& Hogan, 2006), 146, 16.22; (Ruiz-Garcia, Lunadei, Barreiro, \& Robla, 2009), 80, 13.33; (W. Lee et al., 2010), 60, 12; (Abad et al., 2009), $63,10.5$.

(Xu, 2011), 85, 21.25; (Angeles, 2005), 193, 19.3; (H. Lee \& Özer, 2007), 148, 18.5; (Sarac, Absi, \& Dauzère-Pérès, 2010), 83, 16.6; (Li, 2013), 29, 14.5; (Bottani \& Rizzi, 2008), 90, 12.86.

(He \& Da Xu, 2014), 31, 31; (Delen, Hardgrave, \& Sharda, 2007), 89, 11.125; (E. W. Ngai, Cheng, Au, \& Lai, 2007), 84, 10.5; (Gaukler, Seifert, \& Hausman, 2007), 84, 10.5; (Fosso Wamba, Lefebvre, Bendavid, \& Lefebvre, 2008), 72, 10.28 .

Health Care \& Pai, 2008), 85, 12.14; (Jara, Zamora, \& Skarmeta, 2011), 42, 10.5; (Van 
Der Togt et al., 2008), 73, 10.43 .

Tracking System \& Localization

\section{Social Science \& Education}

\section{Resource \\ Management}

Intelligent

Products

Gas Detection

\section{$\underline{\text { Policy Issues }}$}

\section{Security}

Privacy

\section{Others}

Fabrication of Electronic Devices

Internet of Things

\section{General Introduction}

Bibliometric Study
(Schneider, Tautz, Grünewald, \& Fuchs, 2012), 57, 19; (Ruiz, Granja, Prieto Honorato, \& Rosas, 2012), 38, 12.67; (DiGiampaolo \& Martinelli, 2014), 11, 11.

(Cattuto et al., 2010), 95, 19; (Stehlé, Voirin, Barrat, Cattuto, Isella, et al., 2011), 49, 12.25; (Chu, Hwang, Tsai, \& Tseng, 2010), 54, 10.8.

(Welbourne et al., 2009), 93, 15.5; (Kahhat et al., 2008), 84, 12; (Chow, Choy, Lee, \& Lau, 2006), 98, 10.89.

(Meyer, Främling, \& Holmström, 2009), 66, 11.

(L. Yang, Zhang, Staiculescu, Wong, \& Tentzeris, 2009), 61, 10.17.

(Weis, Sarma, Rivest, \& Engels, 2004), 236, 21.45; (Feldhofer, Dominikus, \& Wolkerstorfer, 2004), 200, 18.18; (Chien \& Chen, 2007), 140, 17.5; (Juels \& Weis, 2005), 173, 17.3; (Chien, 2007), 110, 13.75; (Hong et al., 2006), 96, 10.67 .

(Juels, 2006), 393, 43.67; (Garfinkel, Juels, \& Pappu, 2005), 129, 12.9.

(Park, Vosguerichian, \& Bao, 2013), 88, 44; (Sun, Zhang, \& Katz, 2011), 67, 16.75; (Liu, Long, Liao, Duan, \& Fan, 2012), 48, 16; (Fortunato et al., 2008), 105, 15; (Leong et al., 2011), 59, 14.75; (Huang, Liao, Molesa, Redinger, \& Subramanian, 2003), 172, 14.33; (Logothetidis, 2008), 89, 12.71; (Magdassi, Grouchko, \& Kamyshny, 2010), 60, 12; (Luechinger, Athanassiou, \& Stark, 2008), 82, 11.71; (Kamyshny \& Magdassi, 2014), 11, 11.

(Atzori, Iera, \& Morabito, 2010), 536, 107.2; (Gubbi, Buyya, Marusic, \& Palaniswami, 2013), 56, 28; (Miorandi, Sicari, De Pellegrini, \& Chlamtac, 2012), 81, 27.

(Want, 2006), 322, 35.78; (Roberts, 2006), 126, 14; (Sarma, Weis, \& Engels, 2003), 138, 10.62 .

(E. Ngai et al., 2008), 170, 24.28; (Chao et al., 2007), 97, 12.125; (Curtin, 
Post-Print version of: Shakiba, M., Zavvari, A., Ale Ebrahim, N., \& Singh, M. J. (2016). Evaluating the academic trend of RFID technology based on SCI and SSCI publications from 2001 to 2014. Scientometrics 1-24.

http://dx.doi.org/10.1007/s11192-016-2095-y

Kauffman, \& Riggins, 2007), 90, 11.25.

Review

(Dodabalapur, 2006), 163, 18.11; (Wu, Nystrom, Lin, \& Yu, 2006), 123, 13.67; (Preradovic \& Karmakar, 2010), 57, 11.4.

Sensor Networks $\quad$ (Le, Mayaram, \& Fiez, 2008), 105, 15. 